\title{
EXPERIENCES AND EVIDENCE RELATED TO THE LEARNING OUTCOMES IN HIGHER EDUCATION: A DESCRIPTIVE STUDY
}

\author{
Mónica Adriana Villarreal García* and Claudia María García Casas
}

Universidad Panamericana, Mexico

\begin{abstract}
The descriptive study presented here is placed in the context of Higher education. As part of the curriculum transition of the Academic programs of a private University in Mexico City, which went from a model by objectives to learning outcomes. One of the most important things of this change focuses in developing in the students the competence of learning to learn, which incorporates their autonomy in the ability to acquire knowledge throughout the university studies. The design of the programs must guarantee that this competence should be developed in the students. The questions that guided this investigation where: What experiences and evidence scuttled teachers from the operational program of the bachelor's degree in Education? How do they align to the egress profile set out in the official curriculum? Therefore, aims to identify and describe the characteristics that define the experiences and evidence proposed by teachers to demonstrate students learning and how they line up with the established egress profile in the official curriculum of the Education program. Among the preliminary findings, it was found that there is no conceptual clarity that distinguishes the experience of learning evidence in the programmatic proposal of the disciplinary syllabus, nor of its articulation with the egress profile. It was also identified that learning experiences and evidence tend to be mostly focused on the figure of the teacher rather than the student.
\end{abstract}

Keywords: Experiences, evidence, learning outcomes, graduate student profile, programs.

\section{Introduction}

The agreement of the European Higher Education Area, ever since its creation several decades ago, has had a significant change for Universities in various aspects from its structural aspects to profound changes in curricular designs. One of the most important characteristics of this change focuses in developing in the students the competence of learning to learn, which incorporates their autonomy as a personal competence and their ability to acquire knowledge throughout their university studies. In the Bologna Declaration (1999) the member states of the European Union agreed to the creation of a Common Higher Education Area (EHEA - European Higher Education Area) with the purpose of guaranteeing the effectiveness of higher education in Europe. The agreement pointed towards efficiency and effectiveness that were understood as achieving the expected learning results through a well-achieved process. At the same time, this statement sought to adapt the university to the changing needs of society and the advances in scientific knowledge in order to prepare competent professionals. Part of the requirements were that, since 2010, all programs are written in terms of learning outcomes to achieve international competitiveness, transparency in the description of degrees, inter-institutional cooperation and curriculum mobility.

That is why the Panamerican University, located in Mexico in its three campuses (Mexico City, Aguascalientes and Guadalajara) has transited all of its objective programs towards learning outcomes, where the learning experiences and evidences are specified to demonstrate that students achieve the profile of the graduate that University the seeks in each of its careers. 
The Panamerican University`s, mission is to educate people who seek the truth and commit themselves to it, promoting Christian humanism that contributes to the construction of a better world. Its institutional principles are:

- Christian vision of life.

- Inquiry for the truth with scientific rigor.

- Person centered education.

- Training in freedom and responsibility.

- Respect for human dignity.

- Excellence in the work done, with a sense of service to others.

In such a way that the graduate of this University is distinguished by these principles.

At the same time, the School of Pedagogy within the university has the mission of training professionals in education with solid ethical and academic influence, from Christian humanism, on the personal and social reality of the context in which they work. Its vision is to prepare at a national and international level, educational professionals with scientific and academic rigor, so that they perform with ethics, social responsibility and commitment to educational development.

The graduation profile of the Pedagogy students of the Universidad Panamericana is integrated by the eight characteristics that are listed below:

- They pay attention to individual differences and social needs through knowledge of the person, fully respecting diversity.

- They base the principles of educational action through knowledge of the foundations of education and pedagogy in order to assume a critical position before different approaches and educational methodologies.

- They adapt and implement the didactic processes in accordance with the evolutionary stages of human development through the knowledge of the neurophysiological bases of learning, the understanding of the foundations of didactics and the integration of disciplinary knowledge.

- They use critical, autonomous and reflective thinking and apply it to the knowledge of pedagogical theories, development and learning, in order to exercise pedagogy with autonomy, self-regulation and selfcriticism.

- They diagnose, plan, carry out and evaluate educational processes within a specific context through knowledge of that specific educational reality in order to make decisions to assertively solve educational problems.

- They design educational models based on the problematization of reality, data analysis and interpretation in order to respond to the needs and challenges of society.

- They undertake and manage groups and projects oriented towards results through interaction, negotiation and conflict management with different community actors to favor development processes. 
- They generate innovations in different areas of professional work based on its consolidated pedagogical identity with the aim of assuming and responsibly managing its personal and professional development on a permanent basis.

\section{Academies and learning outcomes}

To achieve the student's graduation profile, the School of Pedagogy has divided its study plan in five Academies which are: Foundations of education and Pedagogy, whose object of study is man in terms of educability, the Academy of Didactics and curriculum, whose object of study are the Actors and teaching and learning processes, the Academy of Educational Research whose object of study are the paradigms, approach and methods that have impacted educational research, the Academy of Management and educational policy whose object of study are guidelines, actions, processes and operation of educational projects and the Educational Guidance Academy whose object of study is the preventive and proactive integral development throughout the person's life process. Each Academy has several subjects under its charge.

Each of the subjects has the following elements established in its syllabus (academic program): institutional learning outcomes, program learning outcomes, subject learning outcomes, educational content, experiences of learning, evidence of learning, evaluation criteria and references. Each teacher strategically plans each of these elements based on the characteristic of the graduation profile in which their Academy impacts, in such a way that the learning result is built in such a way that all the elements remain aligned, so once the learning results are achieved, the students have been fully described in the graduation profile. The next step will be to define the appropriate learning experience based on those learning results and subsequently establish the evidence that will support those learning results. In this sense, it is intended to achieve an integrated planning system in which all the elements are coordinated and aligned to achieve the defined learning result and therefore the established graduation profile. As Biggs (1999) points out "when there is an alignment between what we want, how we teach and how we evaluate, teaching is much more effective than when there is no (alignment) ... traditional teaching theories ignored this alignment".

\section{Background and theoretical framework}

As indicated by different authors, among them Bowden \& Marton (1998) and Biggs (1999), an environment that facilitates quality learning will be characterized, among other elements, by coordinating learning results, the learning methodology, which involves the learning experiences with assessment strategies and the evidence of learning. In such a way that the entire teaching-learning process is coherent, and the actors of said process (teachers and students) are partners in it and achieve what is proposed in their curriculum planning. Therefore, in Higher Education, it is necessary to move from didactics focused on teaching methods to a didactics that prioritize the teaching of a specific discipline, which is capable of encompassing from its planning consistent and aligned learning experiences with the graduation profile in such a way that it is clear how from each subject one contributes to achieve it and therefore achieve what is intended. Therefore, it is important to clarify and clarify what is understood by each element presented in the syllabus.

According to the Qualifications Framework of the European Higher Education Area (2005), "Learning Outcomes are statements of what a student is expected to know, understand and / or be able to do at the end of a learning period. That is, the learning results constitute the expected effects that are to be achieved with learning and express the behavior (action) that the learner must show at the end of the learning process. The results, as they are behaviors, are observable and measurable facts, with which learning can be evaluated. (López Camps, 2005; García Martín et al., 2012). They are defined as statements about what is expected of a learner who knows, understands and / or is able to demonstrate once the learning process is finished (ECTS, 2005). 
The term learning experience arises and is taken from the theory of experience of John Dewey (1954) and later from the theory of experiential learning of David Kolb (1984) in which learning is conceived as a process in which a reconstruction of experience by resolving conflicts between dialectically opposite modes of adaptation and synergistic transactions between person and environment (De Camillioni, 2012). Later, César Coll (2004), now from a socio-constructivist perspective, understands it as a subjective learning experience especially significant from the point of view of the subject. Some of the elements that characterize it are: that it implies an awareness, a break in the chain of meanings associated with the way it is recognized as an apprentice.

Good (1973) defines it as: "as any intentional activity (designed by the department and / or the teacher), whose purpose is to provoke meaningful and demonstrable learning in the student, which takes place in diverse fields, inside and outside of the school (in the classroom, the laboratory, the workshop, the university center, the library, in the enterprises or at home). The learning experience must be organized in such a way that the student develops knowledge, skills, attitudes and relationships that will serve him in his later studies, at work, or for life. Its design must take into account the predominant learning domains, intelligences and learning styles. Likewise, it must aim at the development of the desirable dispositions that the institution has adopted for its graduates" (Good, Carter V., Dictionary of Education, McGraw Hill, s. L., 1973).

In this work, learning experiences are understood as a process of learning construction that involves experiencing, reflecting, thinking, acting and transforming in a concrete educational situation. The learning experience seeks to immerse the student individually in a conscious learning process that gives them the opportunity to fully develop their abilities to do and to relate to themselves, to others, to the context, with diverse resources and while confronting different problems. In short, it seeks for the person to develop their capacity to learn to learn and unlearn in any context and under any circumstance in a significant and permanent way.

Authors such as Coll (2004), Navarro (2011), Camillioni (2012), Monereo (2000), among others agree that the purposes of learning experiences rise the quality of education by focusing it on learning, making the student the protagonist and responsible for it. It is also intended that the student learn by doing, learn to learn and engage in their own process consciously and autonomously.

In pragmatic terms, the design of learning experiences also benefits teachers so that they have more clarity in what they want to achieve, expand the range of methods, techniques, procedures, activities and resources, and in looking for evidence of learning that reflects the learning outcomes were achieved.

Therefore, the competencies to design and develop meaningful and self-regulated learning experiences are key competencies that teachers must have. Without them, teachers cannot cope with their daily tasks adequately as they are basic elements for achieving effective teaching.

For the learning experience to fulfill its function, it must be organized by the set of methods, techniques, procedures, activities, resources, which in turn are aligned to achieve the proposed learning result and which in turn meets the graduation profile.

The method is commonly understood as the way to get to the desired end, that is, a succession of ordered actions that also involve complex procedures. Therefore, method is equivalent to saying order, that is to say "the order that is followed in order to avoid errors and find the truth" (Titone, 1981, p. 479). Didactically it is translated into a rational procedure that leads to the correct perception of what is true and what is useful to build a certain learning. However, it is often pointed out that the method starts from a reasoned guiding principle and that it is normally based on a pedagogical conception. 
Referring to the history of teaching methodology, it is easy to identify two broad categories of methods: ancient or classical methods and modern methods, which are perfectly distinguishable from each other. The classical methods constituted the logical ones, they perceive the learning process as strictly intellectual, and thus subject to intellectual laws of thought. Modern methods are those of the "active school". They are founded on a complexity of cognitive, affective, psychomotor functions and therefore can be called, more properly psychological and global (Titone, 1981).

The technique is a means that serves to specify a moment of a didactic unit or part of the method in the realization of learning. "The techniques are the instruments that can be used along the method's own path. Hence, to achieve its objectives, a teaching method needs to draw on a series of techniques" (Carrasco, 1991, p.14). The techniques constitute a means that serves to specify a part of the method in the realization of learning.

The taxonomy of techniques encompasses those that promote learning, group integration techniques, and sociometric techniques. Therefore, the technique: "It is the one that modifies group dynamics and is the means for carrying out the method" (Villalobos, 2002, page 168).

The term strategy arises from the military sphere and it is a way to achieve victory, so the didactic takes it up to specify the proposed educational objectives and is understood as the guide of actions to be followed, they are always intentional, aimed at an objective related to learning. Monereo defines it as follows: "Decision-making processes (conscious and intentional) in which the student chooses and finds, in a coordinated manner, the knowledge he needs to fulfill a certain task or objective, depending on the characteristics of the educational situation in which the action occurs" (Monereo, 2000, p. 27). The real objective is to help the student learn meaningfully and autonomously the different curricular contents and also improve learning and manage it autonomously and effectively.

The strategy is intentional, conscious, and flexible. It takes into account the characteristics of the student, the nature and characteristics of the learning materials, the demands and criteria of the task to be carried out and the knowledge that the student has.

It can be said then that the difference between technique and strategy is that the reflection about the procedures used to carry out a certain task involves the application of learning strategies and the understanding and use of procedures in solving a certain homework is a technique.

Operationally, Mahgenot (2003) defines pedagogical activity as what the student is told to do. Affirms that it can be easily characterized by the provided instruction and by the expected production, the task includes one or more activities that make sense to the student and that at the same time is supported by resources, thus is carried out in a prepared environment.

Teaching / learning activities are the means by which students commit to learning in both cognitive, affective, and behavioral or behavioral spheres (Cooper, 1999). Some activities are more effective in stimulating cognitive learning, while others seem to reach the affective level more successfully. There are other activities that affect the sphere of behavior more strongly. Teachers will want to shape activities appropriate to the field of learning they seek to modify. (Villalobos, 2003).

Procedures are defined as ways of acting to achieve an end. Some authors, including Bransford and Stein, Pressley, Valls, Zabala, among others, agree that there are algorithmic procedures "when the sequence of actions to be carried out is completely predetermined and their correct execution leads to a safe solution to the problem or homework. On the other hand, when these actions involve a certain degree of variability and their execution does not guarantee the achievement of an optimal result... we are talking about heuristic procedures" (Coll, 2000, p. 20). 
Once the learning experiences are designed, a key moment in the learning process is the evaluation, in which, according to Ahumada (2005), timely, valid, reliable, objective and timely information is obtained on the merit and worth of the construction and learning achievement of a student. To do this, they seek to obtain evidence to support this process. According to Diaz Barriga (2006), the evidence corresponds to the documents or products that are determined to verify learning. The evidences must be directed towards elements that provide information on learning construction processes, that is, demonstrate that during the process some form of learning was presented and is supported by the process of constructive activity of thought and action, which necessarily ends in the elaboration of certain representations of the curricular content in question. Additionally, the evidence seeks to improve the quality and level of learning to ensure its permanence and subsequent application.

Given this, there is a problem regarding all these terms used in Higher Education programs, Monereo (2000), González (2012), Martín Molero (1993) agree on this: "We have witnessed a certain confusion about what we teach: study techniques, learning procedures, cognitive skills, strategies, etc ... and, even today it is not uncommon to observe how these terms are used interchangeably, despite responding to different realities and, above all, to various conceptions about the learning process. teaching - learning, very different" (Monereo, 2000, p. 17). Another difficulty is that the authors do not use the same terms to refer to methods that seem similar: the absence of unified terminology in the field of teaching methods is a proven fact, and that is why it is common in this field to have a multiplicity of expressions referring to the same It is common in the scientific literature on teaching methods to find lists of methods that each author lists according to their experience and knowledge, being certainly infrequent that some authors rely on the work of others (González, 2012), which represents an obstacle for university teachers that lack pedagogical training.

\section{Methodology}

The purpose of the study was to identify and describe the characteristics that define the experiences and evidence proposed by teachers to demonstrate students learning and how they line up with the established egress profile in the official curriculum of the Education program. The questions that guided this investigation where: What experiences and evidence scuttled teachers from the operational program of the bachelor's degree in Education? How do they align to the egress profile set out in the official curriculum?

The methodology used for this study is descriptive. The source of information was the total of syllabus completed by each one of the professors of the School of Pedagogy of the Panamerican University. The syllabus is the program that must be planned and completed in writing before the classes begin each semester. The syllabus is reviewed and authorized by the corresponding Head of Academy. The syllabus contains the following elements: general subject data, institutional learning outcomes, program learning outcomes, in this case the School of Pedagogy, subject learning outcomes, educational content, learning experiences, evidence of learning, evaluation criteria and references. For this study all, the syllabus where scuttled in each one of its parts.

Each syllabus was reviewed to identify its consistency between learning outcomes, experiences and learning evidence. Later, the experiences and evidence of learning were identified by Academy and the compliance with the graduation profile was reviewed.

\section{Analysis and discussion of results}

The analysis and discussion of results was done by each Academia. It was related to the characteristic of the graduation profile that the Academy aims to achieve and to evaluate if it is achieved. 
The Academy of Foundations of education and Pedagogy impacts with the trait: It argues the principles of educational action through the knowledge of the foundations of education and pedagogy in order to assume a critical position before different approaches and educational currents. The learning experiences proposed by the teachers are as follows:

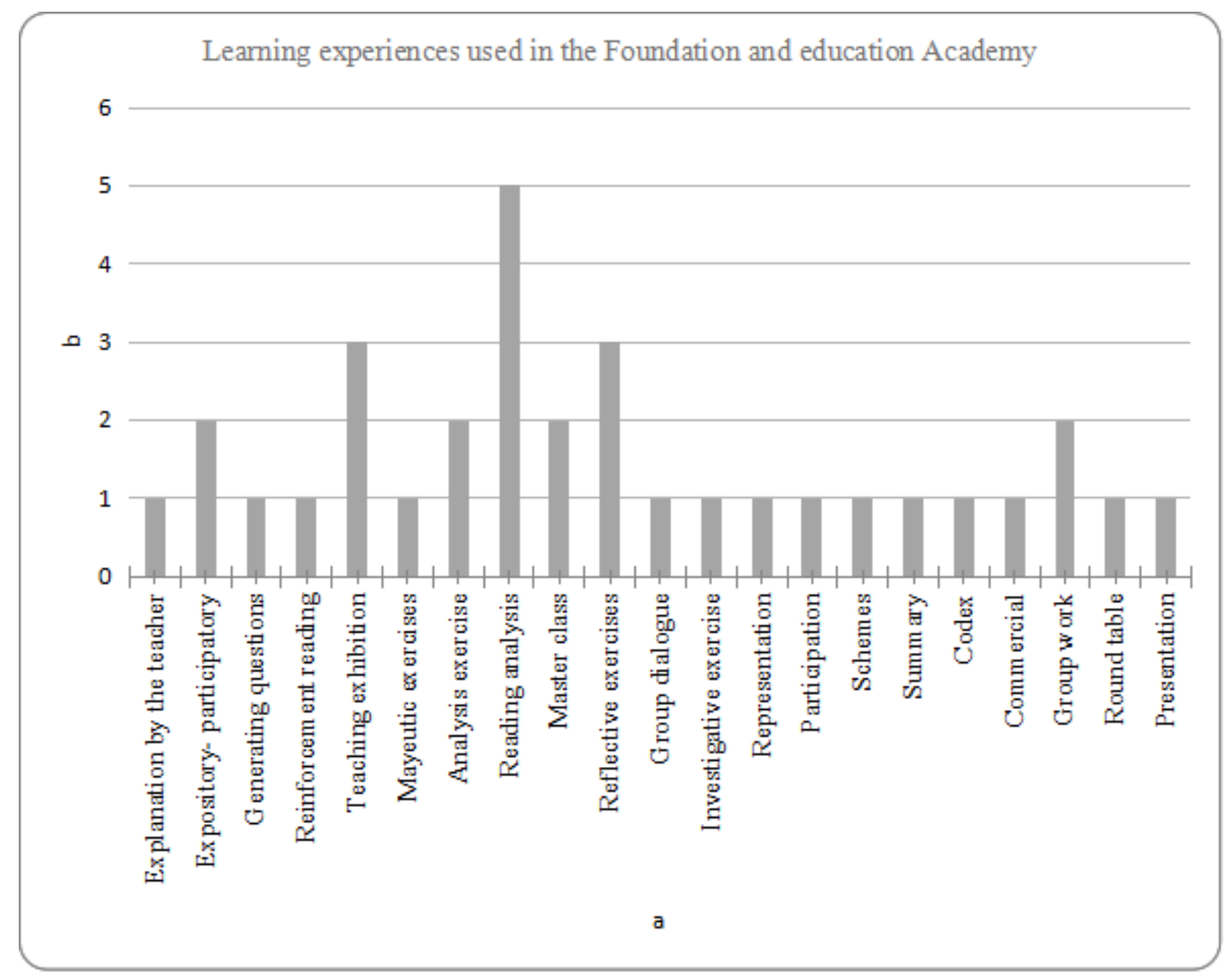

It is evident that within the learning experiences proposed by the professors of this Academy there are multiple terms that refer to it as they are: explanation of the subject, expository, teaching exposition, master class, which constitutes the expository technique. There are activities such as questions, exercises, performances and participation. Procedures that are taken into account are elaboration of diagrams and summaries, as well as strategies such as: mayeutic exercises, analysis of readings, reflective and analysis exercises. There are also some techniques such as group work, round table and group dialogue. It is observed that in a greater percentage the teachers transmit the content and the learning does not fall into the hands of the student. Isolated techniques, activities and strategies that do not guarantee compliance with the graduation profile are used by this Academy. As Clares and Samanes (2009) point out, the different types of techniques and strategies promote different types of learning and skills, a question that is not fully understood by university teachers. However, when analyzing the evidences, they can assess the profile characteristic. Evidence of learning is presented below: 


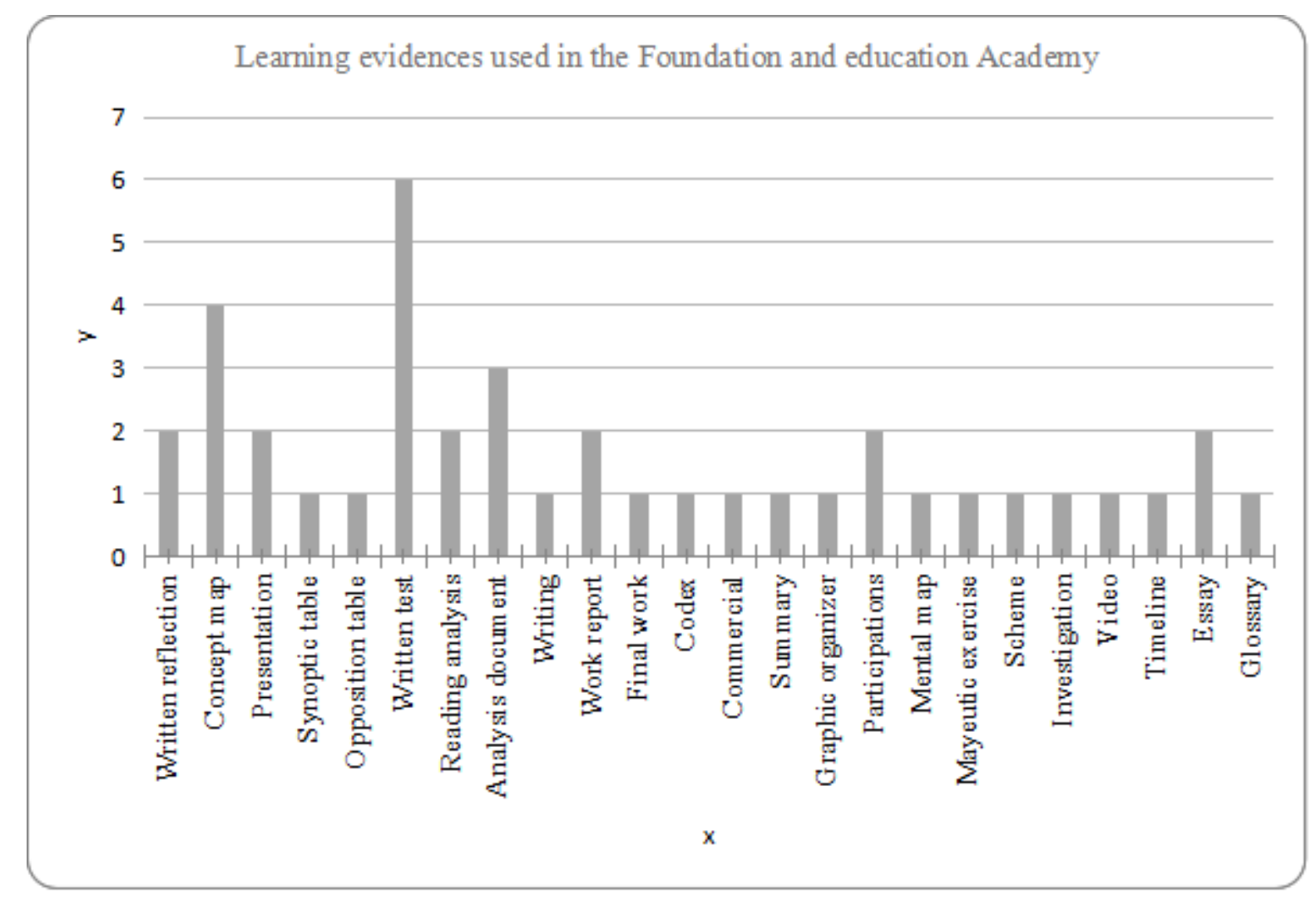

The argumentation can be evaluated through written reflection, analysis documents, essays, mayeutic exercises, writings, and investigations. It is also noteworthy that some terms are repeated both in the area of experiences and evidence of learning, which shows, as Lores and Matos (2017) say, that the terms in relation to teaching, learning and learning are not clearly distinguished.

The Educational Guidance Academy has its greatest impact on the following characteristic of the graduation profile: They diagnose, plan, carry out and evaluates educational processes within a specific context through the knowledge of that educational reality in order to make decisions to assertively solve problems. The learning experiences proposed by the teachers are as follows: 


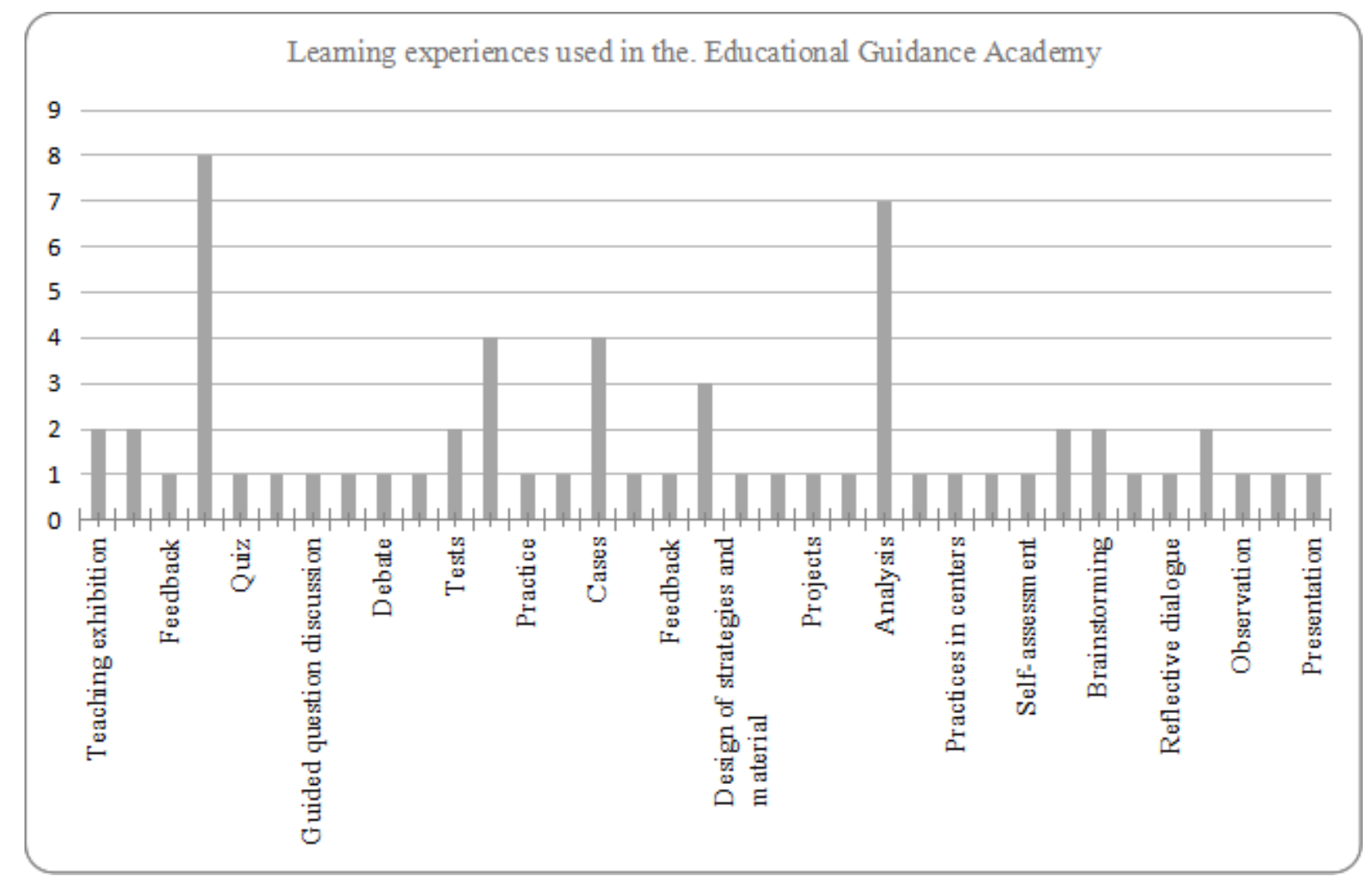

It is evident that within the learning experiences proposed by the professors of this Academy, the presence of techniques such as: teaching exposition, discussion, debate and brainstorming; activities such as: quiz solving, presentations, strategies such as reading analysis and observations and also experiences such as: practices, design of material strategies, preparation of tests, which shows that if the trait corresponding to the graduation profile is largely fulfilled since it is diagnosed in a specific situation and a solution is adapted according to the scope and level of development of the person to whom the activity is directed. However, the experiences are not described as such in the syllabus, but only part of everything they imply is written, which shows that the term is not clear to the teacher, which coincides with Moral Santaella (2012), who establishes that the teacher must also reflect on the development of the teaching and its methodological framework so that they can answer the question of what is the best procedure to follow, how to get to develop adequately and effectively the intended purposes and goals, and in this case learning outcomes. Evidence of learning is presented below: 


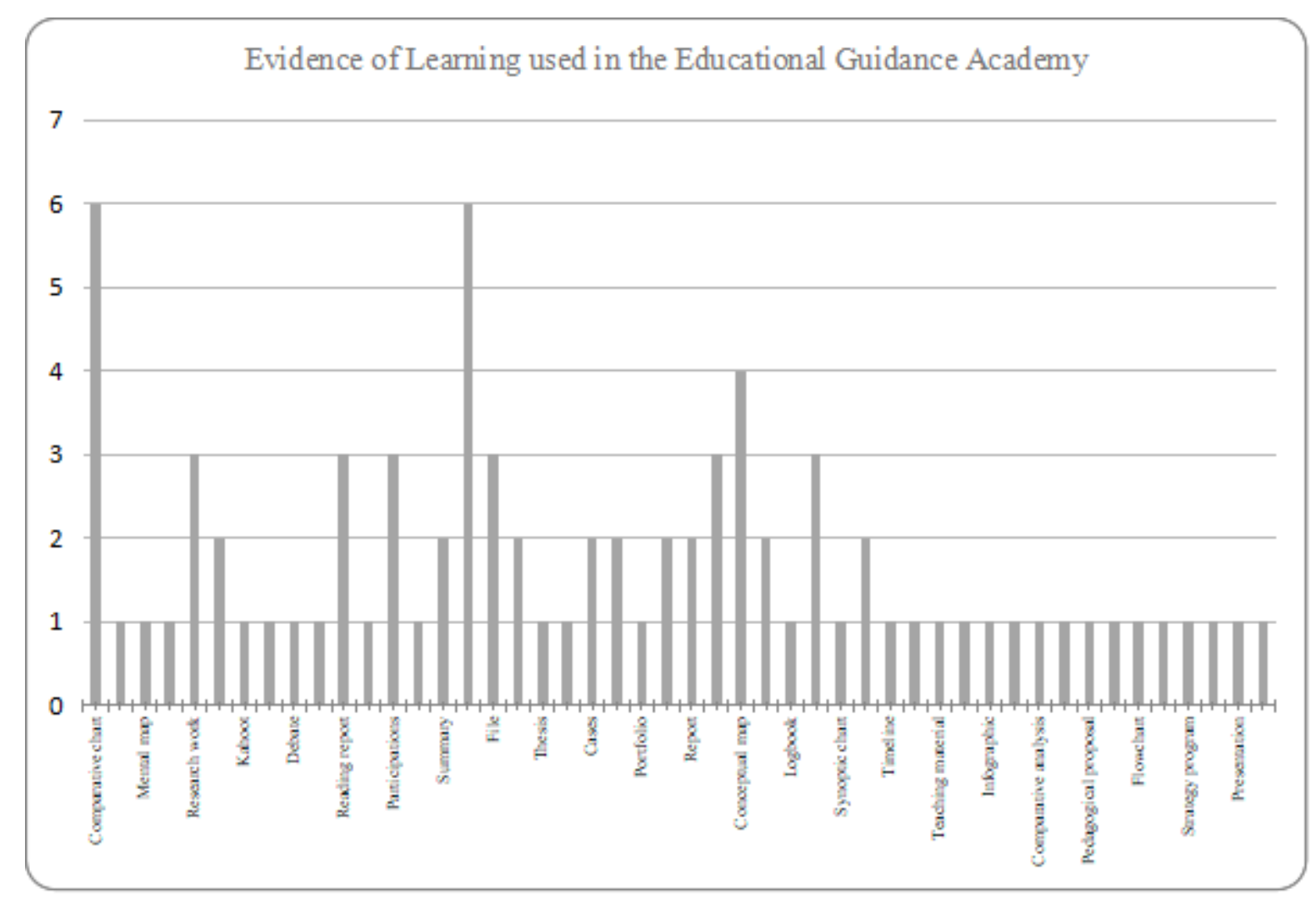

The terms are clear in the evidences however, they cannot verify the profile trait. They would need to be fully described in the syllabus and demonstrate for themselves the achievement of learning outcomes. It agrees with Aguilar de Florez (2011) that the evidences have as a function to verify the achievement of the learning results and if they are not clear, it constitutes a problem to verify these achievements and allow the improvement of these processes.

The Academy of Didactics and Curriculum has its greatest impact on the following two features of the graduation profile: a) They use critical, autonomous and reflective thinking through the knowledge of pedagogical, development and learning theories, in order to exercise the pedagogy with autonomy, selfregulation and self-criticism. b) They diagnose, plan, carry out and evaluate educational processes within a specific context by knowing that educational reality in order to make decisions to assertively solve educational problems. The established learning experiences are as follows: 


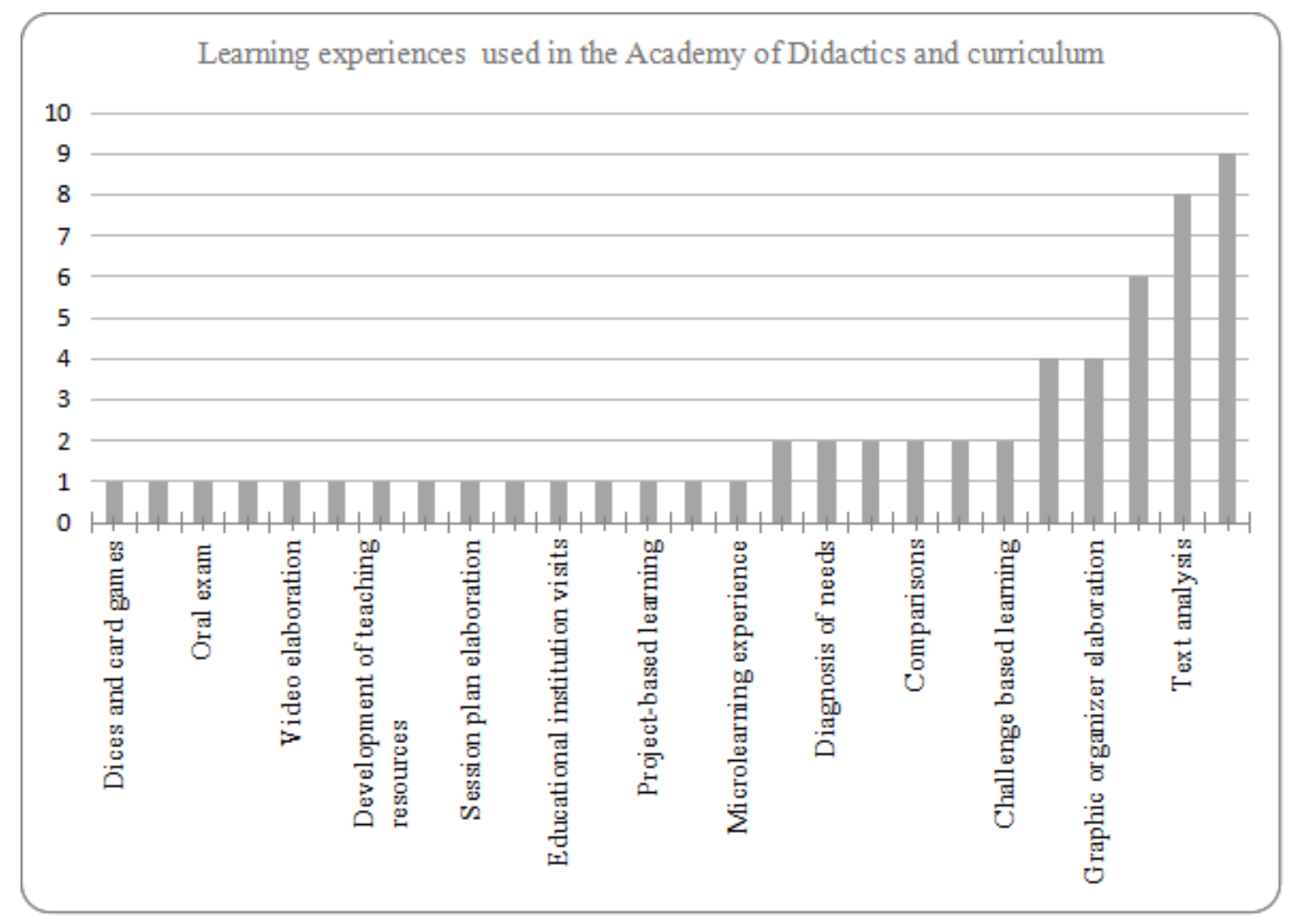

It highlights the broader presence of learning strategies and experiences and only a few techniques and activities. Present strategies are: research, test building, analysis models, project-based learning, research-based learning, text analysis, reading, challenge-based learning. A repetition of terms that refer to the same is observed, as well as a lack of explanation in them. With regard to learning experiences, there are: needs assessment, micro-teaching practices, and visits to educational institutions, video production, and design of recreational activities. It should be noted, as Ariza (2010) supports it, that experience is not enough to ensure learning, but that it is intimately linked to a process of personal reflection, in which meaning is built from the lived experience, therefore that the explanation and description from the syllabus is essential for its clarification. Like the learning strategies, the lack of explanation of them is evident so that it is clear that it is an experience and that it carries within itself techniques, procedures, etc. Therefore, it can be said that the experiences that are described in the syllabus do not reflect the complete experience that is needed to fulfill the characteristics of the graduation profile that impact this Academy. Evidence of learning is presented below: 


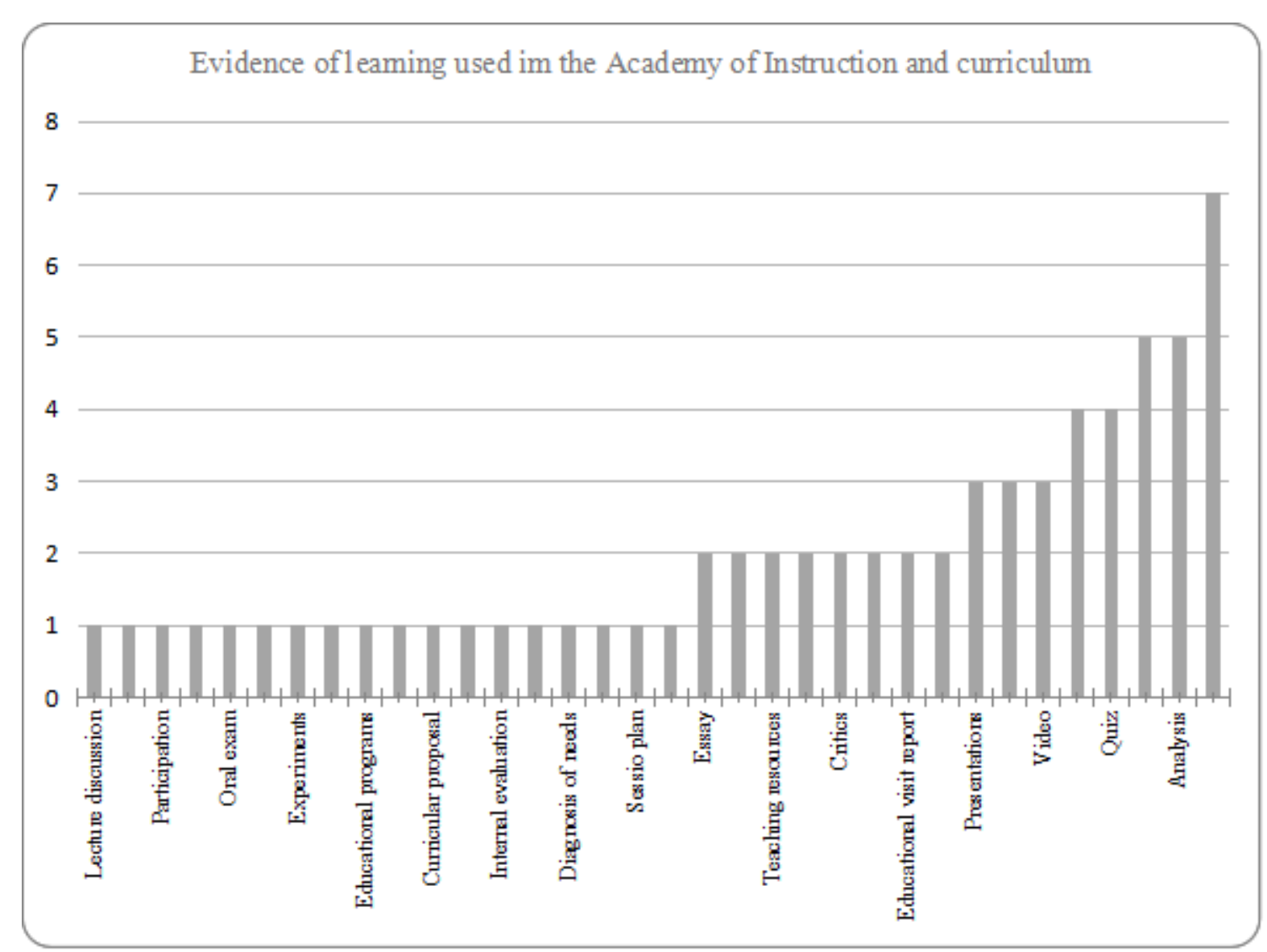

Regarding the evidences, some of them could reflect part of the characteristic of the established graduation profile and part of the learning results, but not completely. For example: the diagnosis of needs that once again is repeated in the experiences and evidences meets a didactic moment that is the actual diagnosis. The elaboration of programs and curricular proposal, meets the didactic moment of planning, however they are missing the realization and evaluation to complete the entire teaching process. With respect to using critical and autonomous thinking, neither the experiences nor the evidence to comply with this feature of the profile are clearly stated, the same evidence must involve students in the responsibility of their own learning process, in their self-management and self-evaluation.

The Academy of Educational Management and Policy has its greatest impact on the following characteristic of the graduation profile: They design educational models based on the problematization of reality, the analysis and interpretation of data in order to respond to the needs and challenges of society, The experiences described in the syllabus are presented below: 


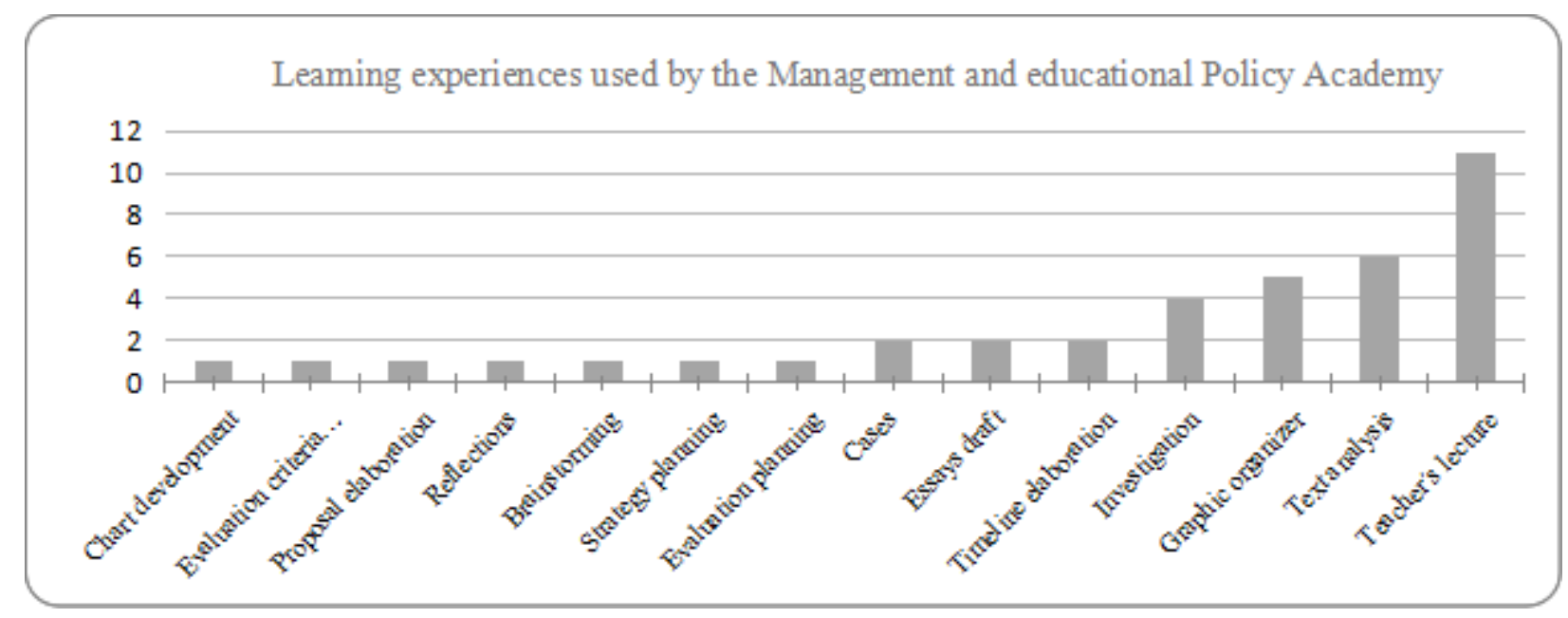

Among the experiences established in the programs of this Academy, the presence of the case method stands out, strategies such as research, planning of evaluation and strategies, activities such as the elaboration of tables, the elaboration of criteria, reflections, exchanges of ideas, procedures such as the elaboration of essays and of timelines. The set established in the syllabus does not demonstrate the achievement of the characteristic of the graduation profile and therefore the learning results established in the subjects.

On the other hand, the evidences described are the following:

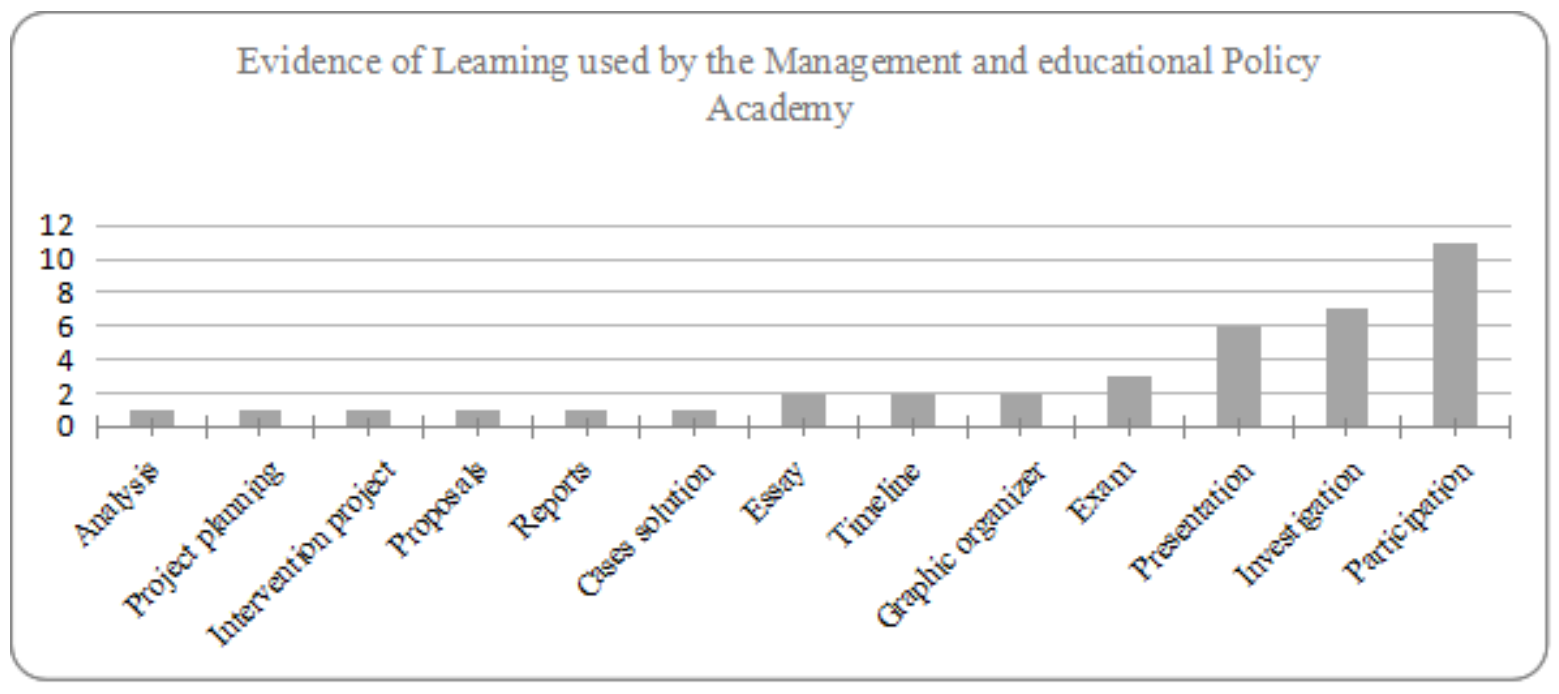

It is shown that in this area of evidence there is a clear confusion between the terms: projects, proposals, planning, presentation, which are not clear what they refer to since they are not properly described, which shows and coincides with Bermúdez and Carreño (2018), in which teachers have the need to reinforce the meaning of the concept of evaluation and the ways to carry it out to verify the learning result. Therefore, the characteristic of the graduate profile cannot be said to be met.

The Educational Research Academy has its greatest impact on the following trait of the graduate profile: They generate innovations in different areas of professional work based on its consolidated pedagogical identity in order to responsibly assume and manage its personal and professional development permanent.

The learning experiences described in the syllabus are as follows: 


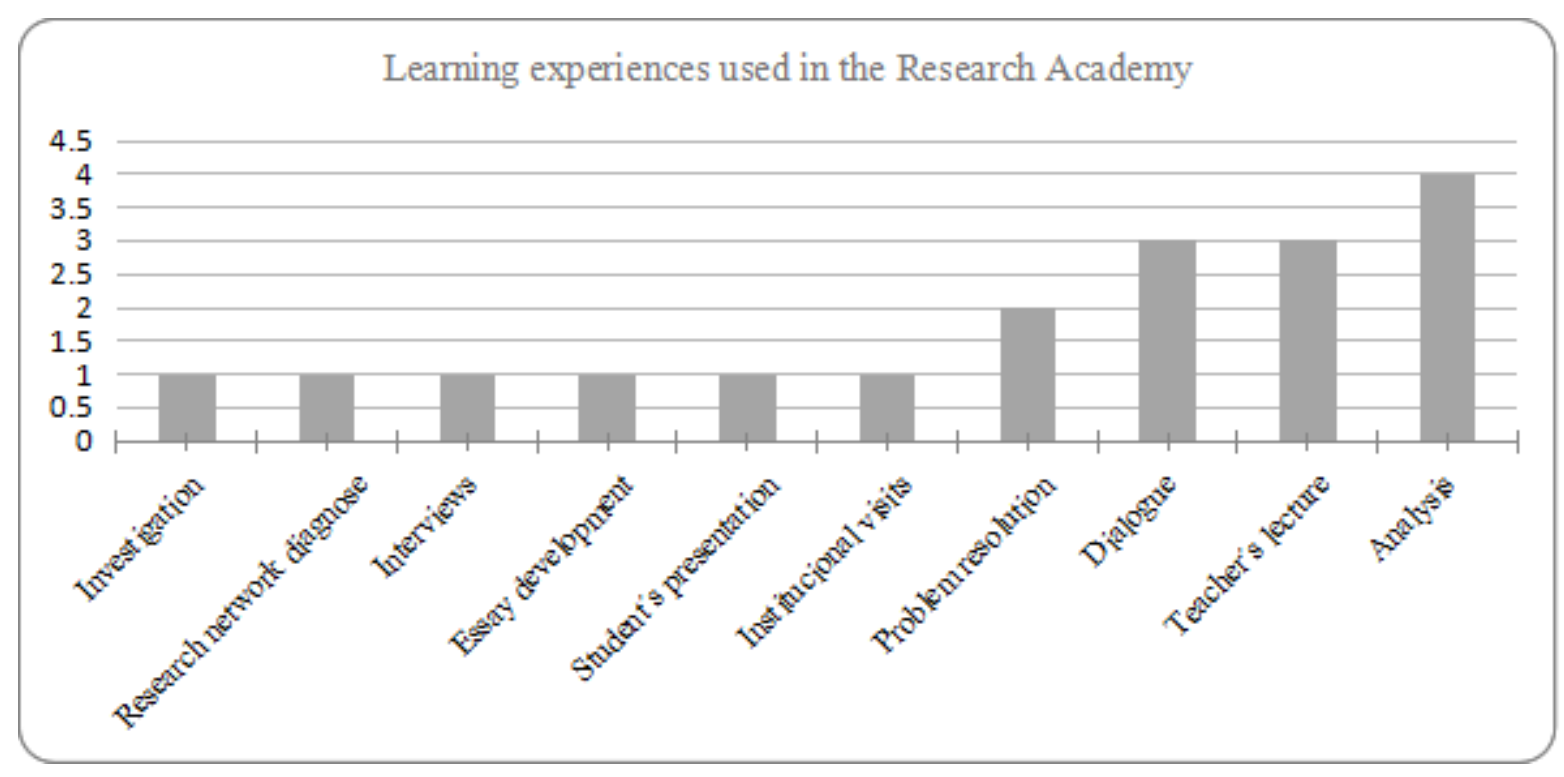

It is shown that the learning experiences proposed in this Academy could be aligned in some way with the characteristic of the graduation profile established through research, analysis, and problem solving. However, the teaching exposure is high, which again shows that the teaching-learning process continues to be centered on the teacher and one must move towards activating the role of the student in their learning process.

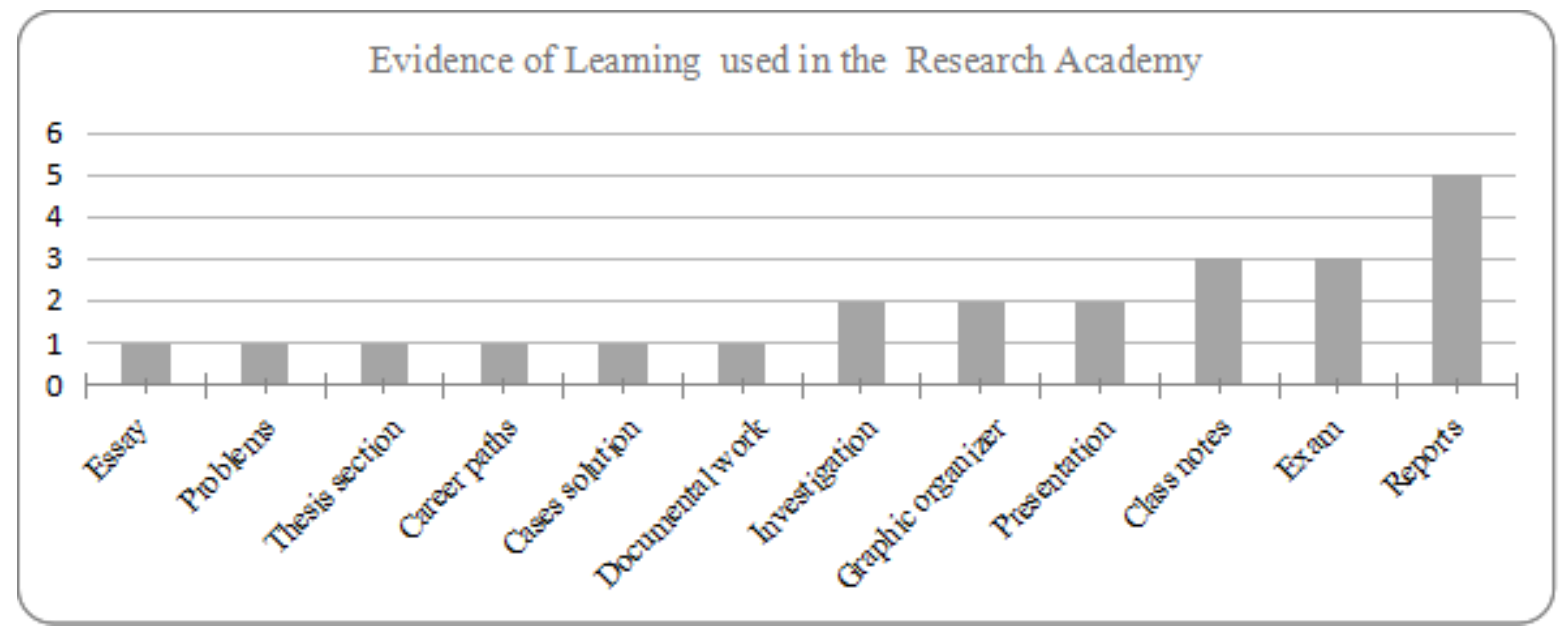

Some of the evidences, such as the resolution of cases, investigations, and essays, do align with the characteristic of the graduation profile established in these Academies, since they demonstrate through the proposed works pedagogical innovations in the different fields. However, unexplained terms and evidences that are not understood are presented again, which does not demonstrate that the evidences are actions planned by the teacher in a conscious way.

\section{Conclusions}

The alignment of learning outcomes with learning experiences and evidence aims to clarify the objective to be achieved and at the same time improve student learning, teaching performance and teaching-learning processes to increase quality, reliability, validity and transparency. Likewise, an adequate alignment allows for punctual monitoring of the learning results that the student is achieving.

From the analysis of the results the following conclusions are reached: 
- With regards of didactics, specifically the part of learning experiences, which involves a methodology, is a field full of terminological and taxonomic difficulties, so it is not always easy for teachers to distinguish between methods, techniques, procedures, strategies, activities and experiences, thus how to choose and design what your teaching work requires becomes a complicated matter for them. Likewise, there is no unification of terms, terms that refer to the same technique are frequently repeated, for example: explanation of the subject, exposition, teaching exposition, master class, all refer to the expository technique.

- In the syllabus, the terms that the teachers establish in the area of learning experiences are used as key words, so it is not fully explained what they mean. It is observed that they are incomplete elements that do not manage to become learning experiences.

- There is a confusion of terms between: method, technique, learning strategy and learning experience as well as a lack of knowledge of the differences between them.

- There is a confusion between experience and evidence of learning, it was frequently observed that the terms were repeated in the same syllabus.

- There is no clarity or identification of the characteristic of the graduate's profile in which each of the subjects must impact, so that most of the learning experiences are detached from the learning result to be achieved and therefore from the characteristic of the profile it intends to fulfill.

- In practice, the learning experience constitutes a complete experience, preceded by a theoretical conception of it, so there is a lack of knowledge of later part, the theory is not presented in the syllabus.

- There is a need to reflect on learning experiences and their conformation based on the conception of the teaching-learning process.

- There is a conceptual confusion between experience and evidence of learning, the concepts of realization and evaluation should be reviewed as didactic moments so that the experiences and the evidence of learning can be properly differenced.

Following this work it is proposed:

- Work from the Academies to: unify terms, concepts, and criteria, identify the student's graduation profile and each characteristic that it's impacted by each subject and thus choose learning experiences based on the purposes of each one of them. In this way, learning experiences can be related to the learning results that are pursued and to the competencies to be developed in the students.

- Adapt the experiences to the Academy, that is, clarify to the teachers what it is intended to fulfill in each of them and align the experiences and evidence of learning, to the characteristic of the graduation profile in which your Academy impacts, to the development of specific competences of each academy and the difference of experiences to develop in each of them.

- Propose interdisciplinary work with various subjects from different academies to enrich and achieve the learning results and therefore the established graduation profile.

- Make a glossary with definitions, classification and taxonomy related to: methods, techniques, procedures, learning strategies and learning experiences to identify what each one is and to be able to design complete experiences described from planning. 
- Classify learning experiences from two axes: the first in terms of its purpose that is, from the learning result to be achieved and the second from the methods, techniques, procedures, strategies and activities that it must contain.

\section{References}

Aguilar de Flórez, E., \& Flórez, S. M. (2011). El Portafolio De Evidencias De Aprendizaje Como Instrumento De Evaluación. Revista Colombiana de Física, 42(3), 305.

Ahumada, P. (2005). La evaluación auténtica: un sistema para la obtención de evidencias y vivencias de los aprendizajes. Perspectiva Educacional, Formación de profesores, (45), 11-24.

Ariza, M. R. (2010). El aprendizaje experiencial y las nuevas demandas formativas. Antropología Experimental, (10).

Bermúdez, A., and Carreño, J. (2018). Promotion of teacher training in the transformation of learning. Spiral, Journal of Teaching and Research, 8 (2), pp. 65 - 78.

Biggs, J. (1999). What the student does: teaching for enhanced learning. Higher education research \& development, 18(1).

Bologna Working Group on Qualifications Frameworks (2005). A Framework for Qualifications of the European Higher Education Area. Copenhague: Ministerio de Ciencia, Tecnología e Innovación. ISBN (internet): 87-91469-53-8.

Bowden, J. \& Marton, F. (1998). The university of learning: Beyond quality and competence. Londres: ED. Koogan-Page.

Casarini, M.(1997). Teoría y Diseño Curricular. México: Trillas

Clares, P. M., \& Samanes, B. E. (2009). Formación basada en competencias. Revista de investigación educativa, 27(1), 125 147.

Coll,C. (2004). Psicología y curriculum. México: Paidós

Diaz Barriga, F. (2006). Enseñanza situada: vínculo entre la escuela y la vida. Mëxico: McGraw-Hill

De Camilloni, A. R. (2012). Situaciones, tareas y experiencias. Actualidades Pedagógicas, (59), 15-32.

De la Fuente Aragón, M. V., McDonnell, D. R., Ayala, M. F., Guillermo, M. M., Cavas, F., \& Martínez, L. (2014). La relación de los resultados del aprendizaje, la metodología docente y la metodología de evaluación. In XII Jornadas de redes de investigación en docencia universitaria. El reconocimiento docente: Innovar e investigar con criterios de calidad (pp. 1862-1876). Instituto de Ciencias de la Educación.

Garibay, B. (2002). Educación centrada en experiencias de aprendizaje. Un enfoque empírico en ingeniería electrónica. De la praxis a la teoría. Recuperado de: http://www. quadernsdigitals. net/datos_web/hemeroteca/r_47/nr_504/a_6928/6928. html\# _ftn1 Socioeducativa, 3(1)

Gómez Pawelek, J. (2007). El aprendizaje experiencial. Argentina: Universidad de Buenos Aires.

González, CG. (2012), Aprender de la experiencia y competencias. Santander, España. Recuperado: http://www.bnm.me.gov.ar/giga1/documentos/EL001173.pdf. Dialnet-AprenderDeLaExperienciaYCompetencias4644809.pdf

González, J. A. (2012). La clasificación de los métodos de enseñanza en educación superior. Contextos educativos. Revista de educación, (15), 93-106.

Lores, D. N., \& Matos, M. S. (2017). Redefinición de los conceptos método de enseñanza y método de aprendizaje. EduSol, 17(60), 3.

Martín Molero, F. (1993). El método su teoría y su práctica. Madrid: Dykinson

Mc Donnell, DR. (2014), La relación de los resultados del aprendizaje, la metodología docente y la metodología de evaluación. Cartagena, Colombia. Recuperado: http://hdl.handle.net/10045/42110

Monereo, C. (2000). Estrategias de enseñanza y aprendizaje. Barcelona: Grao

Moral Santaella, C. (2012). Conocimiento didáctico general para el diseño y desarrollo de experiencias de aprendizaje significativas en la formación del profesorado.

Ros McDonnell, D., Ferrer Ayala, M. Á., Muñoz Guillermo, M., Cavas Martínez, F., \& Ros McDonnell, L. (2014). La relación de los Resultados del Aprendizaje, la Metodología Docente y la Metodología de Evaluación.

Titone, R.(1981). Metodología Didáctica. Madrid: Rialp

Villalobos, J. (2003). El docente y actividades de enseñanza / aprendizaje: algunas consideraciones teóricas y sugerencias prácticas. U de los Andes. Mérida, Venezuela. Recuperado: https://www.redalyc.org/pdf/356/35602206.pdf 